\title{
COMENTÁRIOS SOBRE A LIBERDADE E O LIVRE-ARBÍTRIO DA VONTADE EM AGOSTINHO: UMA REFLEXÃO SOBRE O DE LIBERO ARBITRIO
}

Mariana P. Sérvulo da Cunha'

SÍNTESE - O termo "livre" nunca aparece, em Platão e Aristóteles, como relacionado com a condição moral do homem, pois possui um significado estritamente político. A noção de liberdade, referida ao âmbito da ética, é algo tardio no Ocidente, tendo surgido com o cristianismo. Embora esta noção esteja hoje laicizada, isto é, seja considerada quase que exclusivamente em sua dimensão horizontal, e não na vertical, enquanto relacionada a Deus, nem por isso se deve esquecer a contribuição fundamental de Agostinho na formulação deste conceito. No presente texto toma-se como fonte de análise o diálogo De libero arbitrio.
ABSTRACT - The word "free" never appears in Plato's and Aristotle's texts as related to a moral condition of the man; it has a strictly political meaning. Freedom as ethical concept appears later in the west, introduced by the Christianity. Though this notion today has secular traces, considered almost exclusively in its horizontal dimension and not in the vertical dimension, as related to God, we cannot forget Augustine's fundamental contribution to the formulation of this concept. The present article makes an analysis of the dialogue De libero arbitrio.

É conhecida a abordagem que, na antiguidade principalmente grega, se fazia a respeito da liberdade. Esse tema recebe tratamento diverso e adquire importância nas filosofias cristãs, estando presente em todo pensamento medieval, no pensamento moderno e contemporâneo. Porém, o campo de reflexão a respeito da liberdade, a colocação das questões e eventuais respostas tornaram-se muito diversificadas.

$O$ termo livre - $\varepsilon \lambda \varepsilon v \theta \varepsilon \rho o \sigma$, cujo sentido em grego é inteiramente social - designa a condição do homem livre em oposição ao escravo; nunca aparece, tanto em Platão como em Aristóteles, referido à condição moral do homem, pois a liberdade na antiguidade grega tinha significado estritamente político.

- Centro de Estudos de Filosofia Patristica e Medieval - CEPAME - São Paulo.

\begin{tabular}{|l|l|l|l|l|l|}
\hline VERITAS & Porto Alegre & v. 42 & $\mathrm{n}^{\circ} 3$ & Setembro 1997 & p.493-503 \\
\hline
\end{tabular}


O homem livre é o cidadão. O ideal político de Atenas nos remete à liberdade do cidadão, que é um dos fundamentos da ordem na cidade. Não devemos pensar esta liberdade no sentido do individualismo moderno, que privilegia a pessoa em relação à ordem social.

No estoicismo encontramos uma tentativa de se dissociar a noção de liberdade da politica, de chegar a uma formulação através da qual fosse possível ser escravo no mundo e ainda assim ser livre.

A liberdade em Epicteto consiste em ser livre dos próprios desejos; porém, como o homem sempre está submetido a um determinismo, deve acomodar seu querer aos acontecimentos, conformando-se com eles.

Para Epicteto ("Sobre a liberdade" em Dissertationes; livro IV, 1, par. 1) livre é aquele que vive como quer. Um homem é livre se ele se limita ao que está em seu poder, se ele não vai até um domínio onde possa ser cerceado (op. cit., par. 75). O sábio estóico, imerso em um universo submetido à mais rigorosa determinação, só pode encontrar a liberdade aceitando a ordem universal, isto é, aceitando o que ocorrer, aconteça o que acontecer; desse modo é preciso renunciar aos desejos.

No cristianismo as coisas se passam de outro modo. Ao refletirmos sobre a questão da liberdade e a história desse conceito, importa ressaltar a importância da revelação judaico-cristã: ela modifica as perspectivas nas quais se baseiam os antigos.

O cristianismo, atribuindo a liberdade a Deus, torna possivel a reflexão sobre a liberdade assim como sua reivindicação pelo homem. A liberdade é manifestação da potência de Deus, a criação e o próprio homem são o resultado de uma decisão da liberdade divina.

Encontramos no cristianismo a transferência da noção de liberdade do campo da teologia para o da ética. Só um Deus livre pode dar ao homem a liberdade. É somente a partir da revelação bíblica e em função dela que a liberdade humana torna-se uma das grandes preocupações filosóficas.

O exercício da liberdade representa para o homem uma espécie de cooperação com a obra divina, uma imitação da iniciativa de Deus. O que se passa na perspectiva temporal depende do homem e coloca em jogo sua liberdade. Deus, livremente, criou o homem livre, e a liberdade humana é um reflexo da liberdade divina, visto que o homem foi criado à imagem e semelhança de Deus (Gn 1, 27).

A laicização do tema liberdade não pode nos fazer esquecer sua origem e os antecedentes que remontam até Agostinho. Os conceitos livre-arbítrio e liberdade representam uma grande contribuição do pensamento patrístico e medieval ao domínio especulativo no que diz respeito à tomada de consciência de tais questões.

A nova noção de liberdade, que passou a ser vivenciada como algo pertencente ao interior do homem, é fenômeno historicamente tardio, e será grande, na tradição do pensamento, a influência do conceito de uma liberdade interior. Vemos ocorrer então o divórcio entre a liberdade e a política conforme encontramos na antiguidade greco-romana.

Considere-se que a liberdade agostiniana é por assim dizer vertical, sempre referida a Deus, diferente de uma liberdade por assim dizer moderna e horizontal 
que elimina o plano da transcendência e que entretanto permanece no plano interior, no plano do homem para com ele mesmo, eliminando a relação homem /Deus.

Como se estabelece a nova noção de liberdade?

O cristianismo trouxe muitas mudanças a respeito da concepção do homem e de seu lugar no universo. Suas ações não são determinadas por fatores físicos ou sociais, cada homem deve ser visto como o único autor de sua conduta, tendo responsabilidade integral por ela. É este $o$ ensinamento cristão correspondente à noção de livre-arbitrio.

A doutrina da graça, unindo-se à do livre-arbítrio leva-nos à noção da liberdade cristã.' Ressalte-se que a liberdade não era mais vivenciada no agir e na associação com outros, mas no próprio interior do homem, em suma, ela se interioriza e passa pelo livre-arbítrio. Entretanto, diferentemente de uma liberdade interior que permanece no plano da independência da consciência, num plano, por assim dizer, puramente horizontal, ela se verticaliza, remetendo ao bem supremo.

Para Agostinho a liberdade plena significa acima de tudo a escolha, por livre decisão (através do livre-arbítrio), do sumo bem, da verdade. ${ }^{2}$

Detenhamo-nos agora no diálogo De libero arbitrio do hiponense para tratarmos de uma questão preliminar à liberdade e necessária para a compreensão dela: trata-se da vontade, mais exatamente do livre-arbítrio da vontade.

O De libero arbitrio, inscrito no quadro dos diálogos filosóficos, isto é, aqueles escritos logo após a conversão de Agostinho no ano de 386, é antes de tudo uma reflexão inspirada na busca da origem do mal; em última instância uma reflexão em torno da causa do pecar humano: "De onde vem procedermos mal?" Do livrearbítrio da vontade e não de Deus. O homem afasta-se de Deus voluntariamente, e sendo assim o pecado provém do livre-arbítrio da vontade. Esta, sendo livre, pode nos conduzir à beatitude ou à infelicidade. $\mathrm{O}$ ambiente do diálogo é este. Interessa-nos aqui seguir a linha argumentativa de Agostinho, focalizando nesse diálogo especialmente o papel da vontade e sua liberdade.

No diálogo De libero arbitrio Agostinho transita por vários temas complexos, numa espécie de circunlóquio, como que se desviando do principal tema. $\mathrm{O}$ diálogo parece acabar abruptamente, deixando o leitor mais confuso ainda do que antes do início da leitura, mas nos instiga introduzindo-nos num universo que, para alguém do séc. XX, em contraposição ao séc. IV de Agostinho, revela uma notável reflexão que se refere ao início de determinada corrente do pensamento que se volta para a questão da vontade. Essa foi antes de tudo a ótica que me interessou: rastrear a questão da vontade. O livre-arbítrio é o da vontade, e o mal é seu exercício tendendo para o afastamento de Deus.

Ao refletirmos sobre a origem da noção de liberdade cristã devemos pensar também na polêmica de Paulo em relação à observância da lei judaica .A liberdade cristã significa libertação da lei judaica.: 0 cristão não está sujeito à lei porque tem a graça.

2 Assim, encontramos no bispo de Hipona a distinção entre livre-arbítrio e liberdade tal como vemos, por exemplo, nesta passagem do Enchiridion (XXXII): "Que ninguém, ainda que nảo das obras, se vanglorie do próprio arbítrio da vontade como se a ele coubesse o mérito, que seja a liberdade do bem agir a quem se deve dar a recompensa" "Item ne quisquam etsi non de operibus, de ipso glorietur arbitrio voluntatis, tanquam ab ipso incipiat meritum cui tanquam debitum reddatur praemium, bene operandi libertas".)

3 Agostinho, De libero arbitrio, Corpus Christianorum, Turnholt, Bélgica, 1970. 
Qual a causa determinante da vontade? O que leva cada um a agir bem ou mal?

A causa do mal é a vontade pervertida e a causa desta vontade é antes de tudo uma ausência de causa (causa deficiens). Tal questão será tratada mais adiante.

Conforme A. Solignac," a contribuição de Agostinho para a elaboração do conceito vontade é tripla. Primeiro, ao situar a vontade na mens, ao lado da memoria e da intellegentia, prepara a noção de vontade como faculdade intelectual. Segundo, e essa seria sua contribuição mais original, ele associa a vontade à afetividade, especialmente ao amor, e é assim que influencia a tradição posterior. Terceiro, a vontade seria portanto ao mesmo tempo dependente e independente; suas decisões sempre estariam ligadas aos apetites, aos hábitos, às afecções ou paixões, o que a tornaria vulnerável e mutável. Entretanto, conforme a opção de cada um pela auersio a Deo ou conuersio ad Deum, a vontade torna-se cupiditas ou caritas gerando a felicidade ou infelicidade do homem.

Voltemos ao De libero arbitrio - que é composto por três livros - passando a uma explicitação maior destas questões.

\section{Livro I}

No primeiro livro (cap. XVI, 34- 35) Agostinho procura responder duas principais questões: "o que é proceder mal" e "de onde vem procedermos mal". Chegase a uma definição do que seja cometer o mal: é menosprezar os bens eternos, isto é, afastar-se das coisas divinas e duráveis ("...utrum sit aliud male facere quam neglectis rebus aeternis") e apegar-se às coisas mutáveis e incertas. A segunda questão "de onde vem praticarmos o mal (I, II, 4; unde male faciamus")? nos remete ao livre-arbítrio da vontade. Agostinho afirma, nesse primeiro livro, que o mal moral origina-se do livre-arbítrio de nossa vontade. Visto que a vontade tem a soberania de si mesma, quer dizer, depende somente dela mesma, é dona de si própria, $\mathrm{o}$ ato mau pode ser atribuído a ela.

A vontade situa-se na mente, e a mente submete-se à paixão através da vontade; isto é, a mente não pode tornar-se cúmplice da paixão nem por meio daquilo que se acha dotado de virtude e é igual ou superior a ela (por causa da justiça), nem por meio do que é inferior à mente (devido a essa inferioridade). Enfim, é o próprio livre-arbítrio da vontade que submete a mente à paixão (cap. X, 21).

Pouco a pouco Agostinho vai, nesse primeiro livro, caracterizando a vontade, a ela é atribuída a soberania de si. A vontade (boa ou má) tem poder sobre si própria: pertence a ela querer ou não querer; mais precisamente, diz Agostinho que pertence à vontade querer ou não querer ter uma boa vontade: “...depende de nossa vontade fruirmos ou sermos privados de tão grande e verdadeiro bem [isto é, a boa vontade]. Que coisa está tanto na nossa vontade, como a mesma vontade? (cap. XII, 26)" [“Quid enim tam in uoluntate quam ipsa uoluntas sita est?]

4 In Dictionnaire de Spiritualité, tome XVI, Paris, Beauchesne; verbete: volonté. 
O valor da vontade está dado (cap. XIII, 28), é através dela que levamos uma vida louvável e feliz; pela mesma vontade também podemos levar uma vida vergonhosa e infeliz.

Deparamos-nos aqui com a questão da auto-suficiência da vontade, brecha para uma interpretação pelagiana do texto, que de fato ocorrera. Os pelagianos negavam o pecado original e a corruptibilidade da vontade, afirmavam a onipotência da vontade. Em Agostinho as coisas se passam de outro modo.

Se a vontade fosse tão forte assim, por que sua independência não garantiria a felicidade ao homem? Por que ela não nos impulsionaria sempre na escolha do bem? Aqui é preciso ter em mente alguns aspectos da doutrina cristã professada por Agostinho como também seus objetivos. Refiro-me basicamente a dois pontos: os graus da vontade, isto é, a vontade no homem antes e após o pecado original, e a finalidade do diálogo $\mathrm{De}$ libero arbitrio.

A respeito dos graus da vontade é preciso pensarmos na história da salvação onde há uma matização da força da vontade. Temos a vontade do primeiro casal que podia escolher entre o bem e o mal; a do homem decaído, isto é, a vontade de toda a posteridade de Adão e Eva - que já estaria por sua vez corrompida, sendo sua tendência dirigir-se para o inferior - e a vontade por assim dizer plena, a vontade a ser atribuída ao homem renovado no julgamento final, que se voltaria sempre para o bem, a vontade transformada em liberdade, livre do pecado.

Em todos esses níveis a vontade depende de si própria na escolha do bem ou do afastamento de Deus; porém, a vontade do homem decaído inverte a ordem do uti e frui, isto é, ama o que deve ser amado mas de modo errado, valorizando demasiadamente o que não deve ser valorizado e negligenciando o que deve ser valorizado.

Torna-se inevitável agora tocarmos na questão da graça e do significado da soteriologia cristã. A plena vontade, isto é, a vontade livre será restaurada no dia do julgamento final. $O$ homem poderá então, não somente escolher entre o bem $e$ o mal, tal como podiam Adão e Eva, mas sua vontade se dirigirá somente para o bem, estando livre, liberta de uma má escolha.

O segundo ponto mencionado, a respeito da independência e força da vontade, refere-se à finalidade do De libero arbitrio. Em Retractationes (1. I, 9, 1-6) Agostinho comenta a passagem citada acima, sobre o merecimento da vontade, dizendo que a graça de Deus deve ser levada em conta, ela não suprime a autonomia da vontade, ela a impulsiona preservando a livre escolha.

No diálogo De libero arbitrio a intenção de Agostinho era refutar os maniqueístas, pois eles pretendiam atribuir a Deus, a uma natureza coeterna a ele, a origem do mal; rejeitavam assim a responsabilidade atribuida ao homem pela mal moral negando o livre-arbítrio da vontade. Por isso encontramos nesse diálogo tamanha ênfase dada ao livre-arbítrio da vontade em detrimento da graça. No entanto, o relacionamento do livre-arbitrio com a vontade não deixa de ser tema problemático, pois como preservar o livre-arbítrio e a liberdade do homem se a graça é atuante? Na verdade o papel que Agostinho atribui à graça é de influência, mas não de determinação da vontade. $\mathrm{E}$, ao contrário do que se possa pensar, 
na perspectiva agostiniana quanto mais o homem depender de Deus pela graça, mais livre ele é.

Recorramos a uma significativa passagem da Cidade de Deus (1. XXII, cap. $\mathrm{XXX}, 3$ ). Agostinho aí explica os dois livres-arbitrios concedidos ao homem. Através do primeiro - conferido ao homem quando Deus o criou justo - o homem podia não pecar (como também pecar); o segundo é superior ao primeiro, porque através dele o homem não pode pecar. O livre-arbítrio porém não pertenceria à natureza humana, mas à divina. ${ }^{5}$ Ele é um dom conferido ao homem, dom que o torna partícipe da natureza divina: "Por natureza, Deus não pode pecar; por outro lado, quem participa de Deus só recebe dele a graça de não poder pecar". Em seguida diz o hiponense que visto o homem ter pecado (quando podia pecar), uma graça mais abundante o libertará para que atinja a liberdade de não pecar. Todos aqueles que pertencerão à Cidade de Deus terão vontade livre, isto é, isenta de todo mal e plena de todo bem.

Retomemos a questão que deu ensejo a esses desenvolvimentos refiro-me à questão do merecimento, isto é, a vida feliz atribui-se à boa vontade e a infeliz à má vontade (cap. XV, 31). Por qual motivo, então, nem todos obteriam a vida feliz? $\hat{E}$ voluntariamente que os homens a merecem visto que os justos querem com retidão o que os maus não querem.

$\mathrm{Na}$ verdade a causa dos males não é a vontade, que deve ser considerada um bem como mostrará o livro seguinte, mas sim a vontade corrompida que dirige-se para o transitório. O balanço do Livro I é este, o proceder mal provém do livrearbítrio da vontade (XVI, 35; Nisi enim fallor, ut ratio tractata monstrauit, id facimus ex libero uoluntatis arbitrio).

No Livro seguinte encontramos a célebre demonstração da existência de Deus. Agostinho pretende a partir daí garantir à vontade - independentemente de ser boa ou má - e ao seu livre-arbitrio, seu valor na hierarquia dos seres. Ela é um bem, como toda criação divina. Deus existe e é origem de todo bem, o livrearbítrio portanto é um bem, e Deus não é autor do mal.

\section{Livro II}

No primeiro capítulo do segundo livro Agostinho trata da finalidade da vontade livre: ela foi dada ao homem para que viva retamente. Seria injustiça se ela tivesse sido dada não somente para a realização do bem, mas também para pecar, visto que o pecador é punido. Ora, se ela tivesse sida dada ao homem com esses dois fins - para o bem e mal agir - como poderia ser punido justamente aquele que, servindo-se da vontade, pecasse?

Agostinho se propõe mais adiante (cap. III, 7) discutir três pontos: 1- o modo como se torna evidente que Deus existe [é] (quomodo manifestum est deum esse); 2- se na verdade tudo o que é bem, enquanto bem, procede de Deus (utrum ab illo sint quaecumque in quantumcumque sunt bona); 3- enfim, se será preciso contar,

\footnotetext{
5 "Nam primum liberum arbitrium, quod homini datum est, quando primo creatus rectus, potuit non peccare, sed potuit et peccare; hoc autem nouissimum eo potentius erit, quo peccare non poterit; uerum hoc quoque Dei munere, non suae possibilitate naturae."
} 
entre os bens, a vontade livre do homem (postremo, utrum in bonis numeranda sit uoluntas libera).

Após a discussão sobre a existência de Deus - que passando pelo graus do ser (esse /viuere/ intellegere) atinge os números (que por sua vez são superiores à razão) e a sabedoria - é retomado, no cap. XVIII, o terceiro ponto proposto, isto é, a reflexão sobre o livre-arbitrio. Diz Evódio (o interlocutor de Agostinho nesse diálogo): "convém considerar a vontade livre do homem entre os bens? Uma vez esse ponto demonstrado, concederei, sem hesitação, que Deus no-la deu e que a devia ter dado (cap. XVIII, 47)".

A dificuldade que Evódio levanta em se considerar o livre-arbítrio um bem é que através dele podemos pecar, consequentemente não deveria nos ter sido dado. Agostinho responde a Evódio dizendo que só podemos agir retamente através do livre-arbítrio da vontade, e Deus no-lo deu com essa finalidade. Evódio então contrapõe-se a Agostinho com a afirmação de que o livre-arbítrio deveria nos ter sido dado do mesmo modo como a justiça nos foi dada, isto é, ela é um bem do qual ninguém faz mau uso. Essa afirmação de Evódio levará Agostinho a tratar dos múltiplos bens provindos de Deus, com o intuito de mostrar que há bens maiores, médios e menores e que todos provêm de Deus.

Por exemplo, se formos pensar nos bens corporais, vemos que é uma grande privação alguém não ter as mãos. Há porém aqueles que fazem um mau uso de suas mãos cometendo ações cruéis (par. 48). Ora, reconhecemos que as mãos são um bem corporal e aprovamos sua existênca, o que é recriminado neste caso são aqueles que delas abusam. Devemos considerar a vontade livre um bem - sem ela ninguém vive retamente - e, ao invés de dizer que não deveria ter sido concedida ao homem, recriminar aqueles que dela abusam.

Como dito acima, o núcleo da argumentação do hiponense nesse livro consiste em provar que a vontade livre é um bem, o que nos conduz à conclusão de que deveria nos ter sido dada, porque todo bem é um dom de Deus e todos os bens vêm de Deus.

Agostinho apresenta uma hierarquia de bens. Há três tipos: os maiores, os médios e míninos. Esses dois últimos podem ser bem ou mal utilizados. Através das potências da alma (potentiae animi; cap. XIX, 50), que são bens médios e meio para conseguir os maiores bem, podemos viver retamente.

A vontade é apresentada como um bem, visto que sem ela não podemos viver honestamente (cap. XVIII, 49). Ela difere dos bens corporais, por exemplo, dos olhos, cuja ausência não impede de se viver honestamente, isto é, um cego pode levar uma vida reta. Por outro lado a vontade não pode ser considerada um bem superior, tal como a justiça, que ninguém pode utilizar mal. Entre esses bens superiores estão as virtudes da alma. Ninguém utiliza mal a prudência, a força, a temperança, a justiça. A reta razão está presente nelas, e a reta razão não pode ser mal utilizada (cap. XIX, 50).

Em resumo, as virtudes - sem as quais não se vive honestamente - contamse entre os grandes bens; as potências da alma - sem as quais não se pode viver de modo honesto - são bens médios; e as belezas dos corpos (diversas espécies de corpos] (species corporum) - sem as quais se pode viver honestamente - contam- 
se entre os bens minimos. É importante notar que as virtudes não podem ser mal utilizadas, mas os outros bens, isto é, os médios e os inferiores, podem ser não somente bem utilizados, mas também mal empregados.

A vontade, ao contar-se entre os bens médios, pode ser bem ou mal utilizada. Ela faz bom uso das coisas ao aderir ao bem imutável que conduz o homem à vida feliz; ao aderir ao bem imutável ela nos proporciona os maiores bens.

Apesar de inferiores, os bens desejados pelos pecadores não são maus, como também não é má a vontade livre do homem. No entanto, o problema está na aversão da vontade ao bem imutável quando ela prefere o que é transitório. Essa aversão é caracterizada por Agostinho como voluntária (cap. XIX, 53). E aqui começam os problemas. Não sendo forçado, mas voluntário, esse afastamento gera infortúnio merecido. O mal origina-se da deficiência do livre-arbitrio, da vontade livre, da carência de bem. Tal defeito (isto é, o ato da vontade de afastar-se de Deus) seria voluntário e estaria sob nosso poder (cap. XX, 54).

Chegamos aqui ao núcleo da reflexão no que se refere ao problema do mal. De onde viria o movimento da vontade de afastar-se do bem imutável na direção dos bens mutáveis?

Agostinho responde essa questão (cap. XX, 54) de maneira impactante: "A tal questão eu te entristeceria, talvez, se te respondesse que não o sei. Contudo, não diria senão a verdade. Pois não se pode conhecer o que é nada".

Note-se que apesar desse movimento ser mal, a vontade livre permanece um bem, pois sem ela não podemos viver bem.

Agostinho baseia-se na tradição platônica para tratar do problema do mal, isto é, o mal é apresentado como privatio boni, ausência de bem. Porém, no conceito da tradição platônica são introduzidas modificações. A privatio boni é atribuída à vontade causadora do mal. ${ }^{\circ}$

A causa do mal está na vontade corrompida, ao passo que a vontade corrompida não tem causa. Ela provém antes de uma falta de causa (causa deficiens). Através deste argumento Agostinho reinterpretou a estreita interrelação entre o mal e não-ser - como aparece na ontologia platônica - introduzindo aí a noção de vontade e conferindo-lhe papel central.'

Para Agostinho, diferentemente de Lactâncio e Plotino, o mal não procede da matéria. O novo conceito de vontade suplanta o dualismo espírito/matéria, que foi identificado com o dualismo do ser /não-ser ou bem/ mal na escola de Platão.

O segundo livro termina aqui, diferindo para o terceiro a continuidade da discussão.

\section{Livro III}

No Livro III o hiponense ressalta o papel da ordem universal e nela o do livrearbítrio, que embora sujeito ao pecado é um elemento positivo.

- cf. A. Dihle, The Theory of Will in Classical Antiquity; Berkeley/ Los Angeles/ London; University of Californai Press; 1982, p.128.

7 cf. Dilhe, op. cit., nota 25. 
O livro é aberto com o desenvolvimento da questão apresentada anteriormente: de onde procede a inclinação pela qual a vontade afasta-se do bem universal e imutável em direção aos bens particulares e inferiores.

Se essa inclinação aos bens inferiores fosse natural à vontade, isto é, necessánia, então não haveria culpa alguma no homem. O movimento pelo qual uma pedra é impelida e cai para baixo lhe é natural; mas o movimento da alma (cap. I, 2) em direção às coisas inferiores não é, pois, diferentemente da pedra, ela pode detê-lo.

Agostinho atribui à própria vontade tal movimento (o movimento da alma de afastamento de Deus é voluntário), recordando um argumento apresentado no livro I (cap. XI, 21), o de que nada pode sujeitar a mente à paixão (libido) a não ser a própria vontade. Um elemento inferior não teria poder para tal, ao passo que um igual à mente ou superior a ela não subordinaria a mente à paixão por uma questão de justiça ("...nem um agente superior nem um igual podem constrangê-la [a mente] a esse vexame aviltamento (dedecus), visto que seria uma injustiça"; cap. I, 2).

A vontade pertence ao homem, está em seu poder querer ou não querer algo. Visto que é por meio dela que se comete o mal, ele é atribuído ao próprio homem (cap. I, 3).

Quando queremos algo, queremos com vontade, se não fosse assim não quereniamos de fato. A vontade está em nosso poder e à nossa disposição, portanto é livre (cap. III, 8); Deus previu que o ato da vontade estaria em nosso poder, e não seria vontade se não estivesse em nosso poder.

A vontade, mesmo pecadora, é um bem e permanece na ordem estabelecida por Deus mantendo a dignidade de sua natureza; apesar de manchada pelo pecado ainda permanece superior a tudo que é corporal (por exemplo, à luz): mesmo pecando, a alma nunca chegará a ser matéria (cap. V, 12).

Uma criatura que peca por sua vontade livre é superior àquela que não peca por carecer de vontade livre. Ela é superior não devido à sua corrupção ou aos vícios, mas pelo que conserva da dignidade de sua própria natureza. Isso é semelhante à comparação que Agostinho faz entre um cavalo que se perde e uma pedra que não pode se perder permanecendo no seu lugar, por carecer de movimento e sensibilidade (cap. V, 15). O cavalo sempre será melhor que a pedra devido a sua natureza superior.

Em resumo, segundo a hierarquia dos seres, qualquer alma e mesmo o homem, valem mais do que os seres corporais, não importando o grau de sua corrupção. Para Agostinho, diferentemente de Plotino, que colocava a origem do mal na matéria, toda a criação é um bem, inclusive a matéria; o que existe de fato é uma hierarquia desses bens, onde a matéria não ocupa grau elevado.

A justiça de Deus implica a punição dos pecados - visto que o homem peca por livre vontade e não por necessidade - mas a misericórdia divina pode salvar o homem (cap. II, 4).

Não são as desgraças ou os pecados que são necessários à ordem e perfeição do universo (estas não abalam a ordem do universo), mas as almas enquanto almas, que sendo livres pecam se quiserem ou evitam o pecado. 
Recebemos de Deus tanto o poder de agir bem, querendo, como também o poder de sermos infelizes, agindo mal (cap. XV, 43). Ninguém é obrigado por sua natureza a pecar (cap. XVI, 46). Visto que ninguém está forçado a pecar, nem por sua própria natureza, nem pela do outro, só se peca quando se age voluntariamente. Desse modo não se pode atribuir os pecados a Deus.

No cap. XVII encontra-se a importante discussão a respeito da causa da vontade. Conforme diz Evódio não é sem alguma causa que alguém nunca queira pecar como também jamais queira deixar de pecar.

A causa do pecado seria a vontade, e a causa da vontade seria a própria vontade, porém a vontade desregrada (improba).

Agostinho amarra a discussão conferindo à própria vontade a determinação de si própria, porque se não for a vontade que se auto-determina não há pecado. A causa primeira do pecado seria então a vontade e nenhum pecado seria a causa primeira do pecado. Na verdade só se pode atribuir o pecado a alguém a partir do momento em que se é dono da vontade. Agostinho quer romper o círculo interminável de busca de uma causa levantado por Evódio. No par. 48 ele diz que sendo a vontade a causa do pecado, como Evódio pode indagar sobre a causa do mesmo ato da vontade? "Onde estaria o final da investigação e da discussão? Não obstante, nada podes investigar além da mesma raiz da questão". No par. 49 diz Agostinho que é a vontade ela mesma a causa da vontade, e não se sairia dessa raiz da vontade; ou não é a vontade, e então não haveria pecado algum. "Logo, ou a vontade é a causa primeira do pecado, e nenhum pecado será causa primeira do pecado, e a nada se pode imputar o pecado senão ao próprio pecador". $\mathrm{E}$ conclui esse parágrafo comentando que não sabe por que Evódio haveria de se empenhar tanto em procurar outra causa fora da vontade. Qualquer que seja a causa a vontade, ou ela será justa ou injusta. "Se for justa, quem quer que lhe obedeça não pode pecar. Se for injusta, que cada um resista a ela, e não mais pecará.".

No restante do livro, no que se refere à condição humana após o pecado original, mais precisamente à questão da vontade, encontramos certa ambiguidade. No par. 52 do cap. XVIII Agostinho parece atribuir à vontade um tal enfraquecimento que o homem não poderia fruir do livre-arbitrio na escolha de um bem que desejasse praticar: "Nada de espantoso, aliás, se o homem, em consequência da ignorância não goze do livre-arbitrio da vontade na escolha do bem que deve praticar" ("Nec mirandum est quod uel ignorando non habet arbitrium liberum uoluntatis ad eligendum quod recte faciat").

Mais adiante, no par. 56, ele nega tal necessidade (cap. XX, 56): "Pois, se bem que tenha nascido na ignorância e nas dificuldades, contudo necessidade alguma o obrigava a permanecer nesse estado em que nascera" ("Quamquam enim in ignorantia et difficultate nata sit, non tamen ad permanendum in eo quod nata est aliqua necessitate comprimitur.")

Devemos considerar essa ambiguidade como um excesso da parte de Agostinho, visto que não queria negar o livre-arbítrio, mas sim o contrário.

A continuação do livro não acrescenta nada de novo aos argumentos apresentados. Interessa-nos agora fazer algumas observações. 
A responsabilidade de uma má ação é atribuída ao homem, ao seu livrearbítrio da vontade, visto que ele pode escolher, através de sua vontade, afastar-se ou aproximar-se de Deus. Qual seria então a diferença entre Agostinho - que sabemos afirmar um enfraquecimento da vontade - em relação aos pelagianos que afirmavam a auto-suficiência da vontade? Para os pelagianos a vontade era plenamente executante, isto é, basta direcionarmos a vontade para algo que queremos realizar e realizaremos o desejado. A vontade é potente e não está enfraquecida.

Agostinho, diferentemente dos pelagianos, fala de dois livres-arbitrios concedidos por Deus ao homem. $\mathrm{O}$ homem sempre pode escolher, porém o segundo livre-arbitrio concedido por Deus não permite que o homem peque, e esta é a verdadeira liberdade. Ponto em comum entre Agostinho e os pelagianos é que a vontade sempre é livre, mas em Agostinho encontramos graus de livre-arbítrio, para os pelagianos a vontade sempre é a mesma, plena e liberta. Para Agostinho a liberdade é concedida ao homem como graça de Deus, cabe ao homem seu exercício.

Em Agostinho a vontade será necessariamente plenamente executante (realizo o que quero, realizo o bem que quero) quando doada por Deus ao homem com tal poder, aí não mais haverá cisão entre a vontade, a razão e o corpo, este é o segundo livre-arbítrio. No primeiro livre-arbítrio não encontramos a necessidade do segundo, isto é, podemos também pecar; no segundo necessariamente não podemos pecar pela vontade.

Em Agostinho a vontade é auto-suficiente (isto é, realiza o que deseja; através dela podemos levar uma vida feliz ou infeliz) de modo diferente dos pelagianos pois há graus de vontade. O hiponense afirmava a onipotência da vontade para a escolha ou não da felicidade mas não de modo tão simplista como os pelagianos. Vários fatores - que não estão presentes nos pelagianos - em Agostinho estão imbrincados nessa questão: os graus da vontade, a graça. Após o pecado original, há uma luta entre a vontade, as paixões e a razão para se realizar algo (o bem desejado); para os pelagianos a vontade não se atrita com nada e é sempre executante, basta querer. 